\title{
Contagion Risks and Systemic Stability in Financial Networks
}

\author{
Jingqian Tian $\mathbb{D}$, ${ }^{1}$ Chao Wang $\mathbb{D},{ }^{2}$ Xiaoxing Liu $\mathbb{D}$, ${ }^{1}$ and Longmiao Qiu $\mathbb{D}^{1}$ \\ ${ }^{1}$ School of Economics and Management, Southeast University, Address: Sipailou 2\#, Nanjing 210096, China \\ ${ }^{2}$ School of Finance, Nanjing Agricultural University, Weigang 1\#, Nanjing 210095, China \\ Correspondence should be addressed to Chao Wang; 172305115@qq.com
}

Received 5 August 2021; Revised 15 October 2021; Accepted 9 November 2021; Published 24 November 2021

Academic Editor: Anna M. Gil-Lafuente

Copyright (C) 2021 Jingqian Tian et al. This is an open access article distributed under the Creative Commons Attribution License, which permits unrestricted use, distribution, and reproduction in any medium, provided the original work is properly cited.

\begin{abstract}
An agent-based model is proposed, constructing an evolutionary banking system, where interbank loans and investment strategies are, respectively, determined by liquidity shortage and utility maximization. The causes of systemic risk are then explored based on the evolutionary banking system, which is calibrated by a sample from China. The regulatory interventions indicate the positive effects of increased investment assets, while the negative but inappreciable effects of increased interbank counterparties on contagion risks decrease. This observation hints at the possibility of promoting systemic stability by incentivizing more diversifications in investment assets instead of interbank counterparties. The results also demonstrate the advantages of prudential liquidity requirements, interbank liquidity facilities, and monetary policies from the central bank in promoting banking system stability.
\end{abstract}

\section{Introduction}

After several recent troubled years for the global economy, in which the high integration of financial systems worldwide has been highlighted, systemic risk is now the main focus of a growing number of investigations among both practitioners and scholars [1]. A key mechanism through which the systemic risk operates is balance sheet contagion. The financial network allows for understanding how balance sheets are linked and built up into systemic risk. Therefore, network models have been widely employed in recent years to study the channels through which balance sheet contagion spreads within the financial system [2-4]. Nowadays, stress tests performed by financial authorities have resorted to network models. It is more common to see contagion exercises of several kinds (solvency, liquidity, and overlapping portfolios) as part of the regular stress tests performed by financial authorities. Moreover, the recently introduced macro-prudential policies have tended to rely on network models to estimate the possible impact of their implementation $[5,6]$. The studies on network models of financial contagion have also been growing into a large body of works, which consists of the following main streams: credit default contagion $[7,8]$, common asset contagion $[9,10]$, and funding liquidity contagion [11-13].

Most studies show that contagion risks among banks are divided into two main channels: interbank loans and common assets. On the one hand, the crisis of individual banks indicates that interbank loans of these banks may not be repaid completely, which will hurt their creditors. On the other hand, banks may suffer fire sales due to the loss of common assets. The pioneering studies on interbank loans have explored the interaction between the connectivity of interbank networks and contagion risks, and propose that contagion risks among banks depend largely on the connectivity of interbank networks [14-18]. However, further studies show that contagion risks are limited by that connectivity only when the interbank network is sparse. If the network is dense, contagion risks are largely determined by the properties of individual banks; [19]. With the increasing heterogeneity of individual banks, the structure of the interbank network will be tiered, which means that a small number of the larger banks will have a large number of links, while most banks only have a small number of links. 
Moreover, the stability of the banking system is improved with the tiered interbank network, which is because too-bigto-fail banks will share more shocks in a highly connected banking system [19-23].

Although there have been many studies on contagion risks related to interbank loans, some studies in recent years showed that contagion risks are largely determined by the common assets of banks [24-26]. Banks will sell investment assets to replenish liquid funds if their capital buffers are insufficient, which may result in price drops and thus spread risks to other banks holding common assets [27]. The common assets are induced by the diversification of investment portfolios. Although the diversification of investment assets is beneficial to individual banks according to modern portfolio theory, it is also more likely to trigger overlaps of investment portfolios. As a result, contagion risks will become serious with more common assets formed by the increased diversification [28-32].

According to the above analysis, both interbank loans and common assets have been discussed as systemic risk causes. However, only a few of them explore the endogenous contagion risks based on multiple channels [33, 34]. Furthermore, the banking system is usually constructed without consideration for the dynamic behaviors of banks. Empirical studies based on different countries showed that the relationship between banks continually evolves [35, 36]. Therefore, it is of great importance to analyze the evolutionary features of the interbank network and its impact on contagion risks [17]. In addition, banks usually determine investment portfolios according to their risk appetites with the general rule of maximizing utility $[20,37,38]$. Therefore, referring to Aldasoro et al. [37] on endogenous risk, we construct a banking system based on dynamic endogenous mechanisms to analyze the systemic risk caused by interbank loans and common assets, where factors related to individual properties are also considered. Our main goal is to clarify different systemic risk causes and further reveal different formations of contagion risks. We show how the systemic risk is captured by interbank loans, common assets, and financial leverage. We hope that our work will improve the systemic stability of the banking system by exploring some prudential regulatory policies.

As for the contributions of this paper, we present a pioneering framework for exploring systemic risk causes from the perspective of behavioral finance. Despite interbank loans and common assets having been widely discussed as systemic risk causes, we refer to their dynamic effects on contagion risks in an endogenous banking system. In addition, we divide the systemic risk into different components, in line with different causes, to demonstrate its formation mechanism. We also compare the difference between secured and unsecured loans in dealing with systemic risk prevention from the perceptive of both the interbank market and the central bank. The results indicate that some distinctive regulatory references hint at promoting the stability of the banking system.

The study proceeds as follows. Section 2 describes the agent-based model to simulate the banking system. Section 3 shows the parameterization and validation of our model.
Section 4 discusses systemic risk causes according to empirical results. Section 5 analyzes some regulatory interventions according to systemic risk causes. Finally, Section 6 concludes the study.

\section{Agent-Based Model}

A financial system consisting of $N$ banks and $M$ assets is considered, where the balance sheets of banks include liquid funds, external investments, and interbank lending on the left side, and deposits, interbank borrowing, and net worth on the right side. The liquid fund held by the bank $i$ is represented by $c_{i}$, the deposit is represented by $d_{i}$, and the net worth is represented by $w_{i}$. Additionally, the external investment is $e_{i}=\sum_{j=1}^{M} w_{i j} e_{i} p_{j}$, where $w_{i j}$ indicates the proportion of assets $j$ held by bank $i$, and $p_{j}$ is the price of the external asset. Interbank lending is represented by $l_{i}=\sum_{k=1}^{N} l_{i k}$, and $l_{i k} \geq 0$ indicates the funds that bank $i$ lends to bank $k$. Therefore, interbank borrowing is $b_{i}=\sum_{k=1}^{N} l_{k i}$.

The balance sheet constantly updates along with the evolution of the banking system. These updates are done for all banks for all steps. Every update is divided into three phases. At the beginning of Phase 1, the banks hold liquidity from the end of the previous period. The update starts with banks paying the required reserves and excess reserves. In Phase 1, the banks invest their remaining liquidity into the planned level of activities. From the planned level and the current level of investments, as well as the current liquidity, the banks determine their liquidity demands and go first to the interbank market to fulfill them. However, if the banks still have liquidity demands, they will ask for central bank loans. In Phase 2, the banks obtain a stochastic return for all investments, which might be either positive or negative. After that, the banks can either receive further deposits from the households or suffer deposits with drawings. Finally, the banks will be liquidated in Phase 3. The banks then pay back all investments that were made in a previous period and pay interbank loans, deposits, and interest at the end of this period. In Period 0, all banks are endowed with initial values, referring to the actual banking system. Notably, the initial interbank loans are determined by the widely used maximum entropy approach. According to the above mechanism, the balance sheet is updated in the following sequence.

2.1. External Investments. External investments can be divided into risk-free investments and risky investments. According to the CRRA utility function, the optimal external investments is determined by

$$
\tilde{e}_{i}^{t}=r_{c}{ }^{-\left(1 / \eta_{i}\right)}\left[1+\varphi_{i} r_{i}^{t}-\frac{1}{2} \eta_{i}\left(\varphi_{i} \sigma_{i}^{t}\right)^{2}\right]^{1-\eta_{i} / \eta_{i}},
$$

where $\varphi_{i}$ represents the proportion of risky assets, $r_{i}^{t}$ and $\sigma_{i}^{t}$, respectively, represent the expected return and volatility of a risky investment, $\eta_{i}$ is the risk aversion coefficient, and $r_{c}$ represents the financing cost. Although external investments update in each period, only surpluses and deficits, which account for a small proportion of assets, are rebalanced. Therefore, no fire sales are triggered. 
2.2. Liquid Funds. Given the prudential liquidity requirements in the modern banking system, both the deposit reserve ratio and the liquidity coverage ratio are considered. Given the requirement on the deposit reserve ratio $\alpha$, the liquid fund is expressed as $\widetilde{c}_{i}^{t}=\min \left\{d_{i}^{t-1}+w_{i}^{t-1}-\widetilde{e}_{i}^{t}, \alpha d_{i}^{t-1}\right\}$. Additionally, the liquid fund should also meet the liquidity coverage ratio requirement, and therefore, it updates as $\tilde{c}_{i}^{t}=\min \left\{\widetilde{c}_{i}^{t}, \sum_{j=1}^{N} b_{j i}-\sum_{j=1}^{N} l_{j i}+\alpha d_{i}^{t-1}-\left(1-\varphi_{i}\right) \tilde{e}_{i}^{t}\right\}$. The banks will then borrow from counterparties through the interbank market, initially to fulfill the liquidity shortages.

2.3. Interbank Loans. According to the liquid funds, banks are divided into two categories: debtor banks, which are in danger of bankruptcy due to the shortage of liquid funds, and creditor banks, which have liquidity surplus. Given the fact of tiered interbank networks, debtor banks usually select creditor banks with a size preference to issue loan applications until there is no excess liquidity allocation. As a result, interbank loans are determined. Thereafter, the liquid funds of debtor banks and creditor banks are renewed as $c_{i}^{t}=\widetilde{c}_{i}^{t}+\sum_{j=1}^{N} l_{j i}$ and $c_{i}^{t}=\widetilde{c}_{i}^{t}-\sum_{j=1}^{N} l_{i j}$. We will then explore two cases in the simulations, dealing with secured and unsecured interbank loans.

2.4. Central Bank Loans. Given the major role of monetary policies on the financial market, we assume that debtor banks will ask for central bank loans if they still have liquidity demands after the interbank loans. Three typical monetary policies for liquidity facilities from the central bank are modeled. The first one is related to the reserve ratio requirement. The second one is known as central bank loans without collateral. The last one terms open market operations where the central bank loans are secured. The central bank checks whether the banks have the necessary securities to provide the loans in the second case. If the banks have insufficient securities, the central bank will not provide full liquidity demands. We take risk-free investments of the banks as securities, and the renewed external investments of debtor banks are therefore given as follows:

$$
e_{i}^{t}=\max \left\{\left(1-\varphi_{i}\right) \widetilde{e}_{i}^{t}, \tilde{e}_{i}^{t}-\alpha d_{i}^{t-1}+\widetilde{c}_{i}^{t}+\sum_{j=1}^{N} l_{i j}\right\}
$$

and the liquid funds of debtor banks are equally supplied.

2.5. Deposits. According to Georg [20], the fluctuation of deposits can be described by the following process: $d_{i}^{t}=(1-\gamma+2 \gamma \chi) d_{i}^{t-1}$, where $\chi$ is a random variable between $[0,1]$ and the parameter $\gamma$ is used to measure the volatility of deposits.

2.6. Investment Returns. The fixed returns are calculated on the risk-free interest rate, and the determination of floating returns depends on the prices of assets. Overall, the movement of the asset price in the financial market conforms to the lognormal distribution. It is therefore defined as follows:

$$
p_{t}=p_{t}-1\left[\exp \left(r_{f}-\frac{1}{2} \sigma^{2}\right) \Delta t+\sigma \sqrt{\Delta t z_{t}}\right]
$$

where $r_{f}$ represents the return of risk-free investment, $\sigma$ represents the volatility of asset prices in each period, and $z_{t}$ is the standard normal distribution.

2.7. The Liquidation. At the end of each period, it should be confirmed whether a bank is bankrupt or not according to its net worth. The net worth is represented as follows:

$$
w_{i}^{t}=c_{i}^{t-1}-\left(1+r_{d}\right) d_{i}^{t-1}+\sum_{j=1}^{M} e_{i j}^{t-1} p_{j}^{t}+\left(1-\omega_{i}^{t-1}\right)\left(1+r_{f}\right) e_{i}^{t-1}+\left(1+r_{b}\right)\left(l_{i}^{t-1}-b_{i}^{t-1}\right) .
$$

The net worth will be renewed until there is no bankruptcy in the system. It is notable that both interbank loan payments and asset prices have a dynamic equilibrium for the bankrupt banks [34], so that spiral contagions are formed. Therefore, the realized payment is as follows:

$$
q_{i}^{t}=\min \left\{\left(1+r_{b}\right) b_{i}^{t}, c_{i}^{t}-\left(1+r_{d}\right) d_{i}^{t}+\sum_{j=1}^{M} e_{i j}^{t} p_{j}^{t}+\left(1-\omega_{i}^{t}\right)\left(1+r_{f}\right) e_{i}^{t}+\left(1+r_{b}\right) \sum_{k=1}^{N} \pi_{i k}^{t} q_{k}^{t}\right\}^{+}
$$

where $\pi_{i s}=l_{i k} / b_{k}$ means the relative loan of the bank $k$ to the bank $i$ and $r_{d}$ and $r_{b}$ denote the interest rate of deposits and interbank loans. The price is determined by the proportion of investment assets for sale due to bankruptcies $p_{j}^{t}=\exp \left(-\beta \sum_{i \in F}^{N} s_{i}^{t}\right)$, where the parameter $\beta$ is used to measure the elasticity of prices, $s_{i}$ is the proportion of assets sold by the bankrupt bank $i$ to the total holdings of the assets, and $F$ represents the set of bankrupt banks. 


\section{Parameterization and Validation}

We initialize the banking system according to the balance sheets of 100 individual banks that come from the Chinese banking system in 2020. The sample consists of almost all banks in the three main categories, namely state-owned commercial banks, share-holding commercial banks, and city commercial banks. Their assets cover about $67 \%$ of the whole banking sector. All the banks have access to the interbank market, and all the processes are described in Section 2. The risk aversion coefficient $\eta$ and the proportion of risky assets $\varphi$ are consistently determined by the empirical result of our sample. We further assume that the number of investable assets is 100 . In the benchmark case, the number of assets held by banks is 10, and the banks evenly invest in all assets. The price impact is notoriously hard to estimate. Therefore, we follow Amihud and Noh [39], who find a median price impact of 10 basis points when 10 billion worth of assets are sold. We limit the downside of price to 0.8 in the benchmark case to measure the impact of fire sales on contagions. The required deposit reserve ratio $\alpha$ is 0.1 according to regulatory requirements. The level of deposit fluctuations $\gamma$ equals the deposit reserve ratio in extreme cases. The average number of interbank counterparties is 10 according to the sample. The risk-free interest rate, deposit interest rate, interbank interest rate, and financing cost are 0.02 for simplification. To analyze the dynamic evolution of contagion risks, 200 periods of experiments are carried out and 100 times simulations are repeated as the results to increase the robustness. Furthermore, it is necessary to remove bankrupt banks and introduce the same number of banks to ensure the stability of the system.

Validation exercises confirm that the model produces a banking system resembling the real market. The balance sheet validation is listed in Table 1 , where the empirical data are derived from the sample and the simulated data are averaged over its evolution. It shows that all simulated balance sheet ratios are closely in line with empirical results. The comparison of observed versus simulated ratios shows that our agent-based model resembles the real market. We further perform a distribution property comparison from the perspective of total assets and interbank loans. Many empirical findings indicate a power-law tail in the distribution of both total assets and interbank loans. This is also validated by original empirical results as shown in Figures 1(a) and 2(a). Correspondingly, Figures 1(b) and 2(b) demonstrate the output from an average evaluation of the evolution. The comparison of the two distributions shows a good overall match in the statistics of power-law tails.

\section{Empirical Results}

Incentives of systemic risk are divided into two main aspects: liquidity shortages and investment losses. The first is tailored to distress in funds, while the second is tailored to distress in assets. As a result, we define two coefficients to measure the structures of interbank loans and external investments as follows:

$$
\begin{aligned}
& D_{i}^{\prime}=\sum_{j \neq i}^{N} \sum_{k=1}^{N} \sqrt{\sum_{k=1}^{N} l_{i k} \cdot \sum_{k=1}^{N} l_{j k} \cdot\left(l_{i k} l_{j k}\right)^{-1}} \\
& D_{i}^{\prime \prime}=\sum_{i}^{N} \sum_{j \neq i}^{N} p_{k} \sqrt{\sum_{k=1}^{N} e_{i k} p_{k} \cdot \sum_{k=1}^{M} e_{j k} p_{k} \cdot\left(e_{i k} e_{j k}\right)^{-1}},
\end{aligned}
$$

where $D^{\prime}$ and $D^{\prime \prime}$ are, respectively, used to depict the concentration of interbank loans and the overlap of external investments.

As the core capital buffer, net worth plays a decisive role in bankruptcy. Therefore, the leverage level of banks, represented by $L$, is also considered. We use the average bankrupt bank to define systemic risk. The correlation coefficients of $D^{\prime}, D^{\prime \prime}$, and $L$ on systemic risk are shown in Table 2. We divide the systemic risk into market risk, liquidity risk, and devaluation risk, which are caused by investment losses, liquidity shortages, and fire sales to clarify different systemic risk causes. They contribute 0.0044, 0.0376 , and 0.2981 , respectively, to systemic risk. It is noteworthy that only cases with bankruptcy in the experiment are used for systemic risk calculation.

According to experimental results, $D^{\prime \prime}$ is closely correlated with the market risk, since that the market risk directly measures the expected investment losses. With the increasing investment overlaps, more banks will suffer shocks at the same time. On the other hand, interbank loans provide more channels for contagions when banks are bankrupt. As a result, $D^{\prime}$ shows a positive effect on market risk. Lastly, the positive correlation between $L$ and market risk indicates that leverage determines whether a bank goes bankrupt.

One of the advantages of the agent-based model is exploring liquidity risk by simulating the deposit fluctuation of individual banks. After market risk, bankruptcies caused by liquidity shortages are listed in the column on liquidity risk. It shows a definite decline in the correlations of $D^{\prime \prime}$ and $L$ with liquidity risk when compared to market risk. However, $D^{\prime}$ generally remains at the same level. The results indicate that defaults of interbank loans make a principal contribution to the liquidity risk.

Many experimental results show that fire sales of assets will lead to disastrous losses. This conclusion is also validated by the devaluation risk, which is much higher than liquidity risk and market risk. It also points out that fire sales are positively correlated with $D^{\prime \prime}$. When the liquidation of bankrupt banks triggers fire sales, banks that held the same assets also suffer from the devaluation. The overlap of external investments is therefore the direct cause of the devaluation risk. However, it is worth noting that the correlation between $D^{\prime}$ and devaluation risk decreases a great deal when compared to the liquidity risk and the market risk. Though many results have highlighted the spiral effect of common assets and interbank loans on fire sales, our results indicate that interbank loans provide an inappreciable promotion for contagions in the cascade of fire sales when compared to common assets. This conclusion will be further validated in the following discussion. 
TABLE 1: Balance sheet validation.

\begin{tabular}{|c|c|c|c|c|c|c|}
\hline & Cash & Interbank lending & Investment & Interbank borrowing & Deposit & Net worth \\
\hline Empirical data & 0.1087 & 0.0311 & 0.8603 & 0.0152 & 0.9054 & 0.0794 \\
\hline Simulated data & 0.1713 & 0.0378 & 0.8287 & 0.0378 & 0.8785 & 0.1215 \\
\hline
\end{tabular}

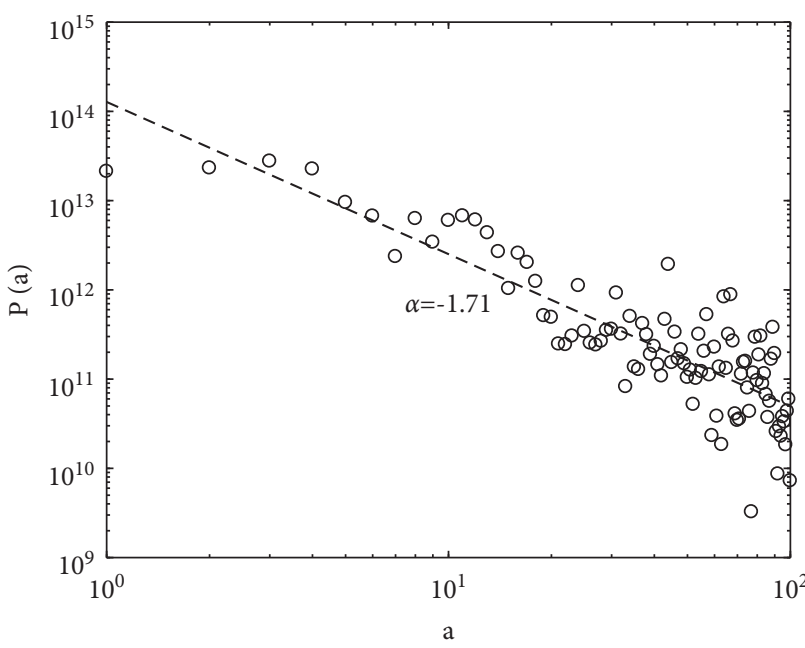

(a)

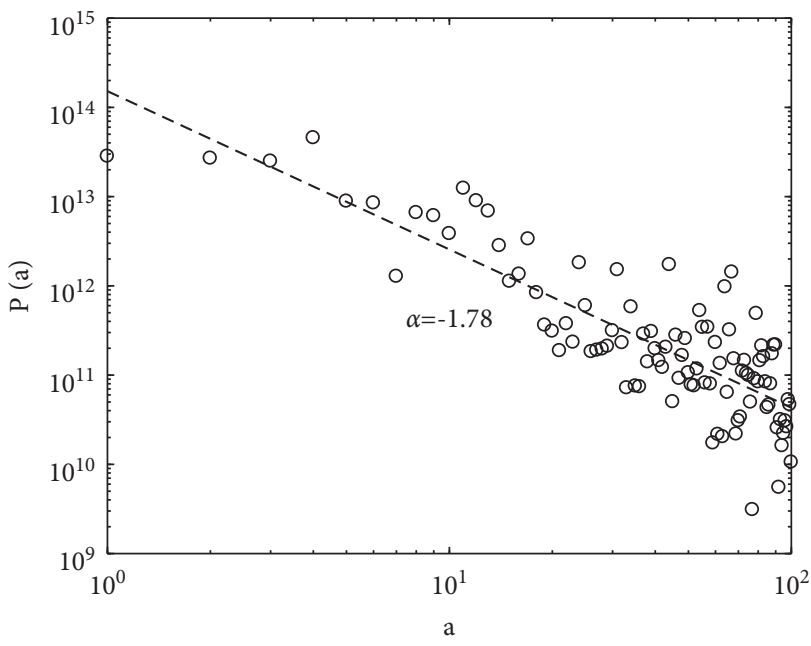

(b)

FIGURE 1: Distribution of total assets.

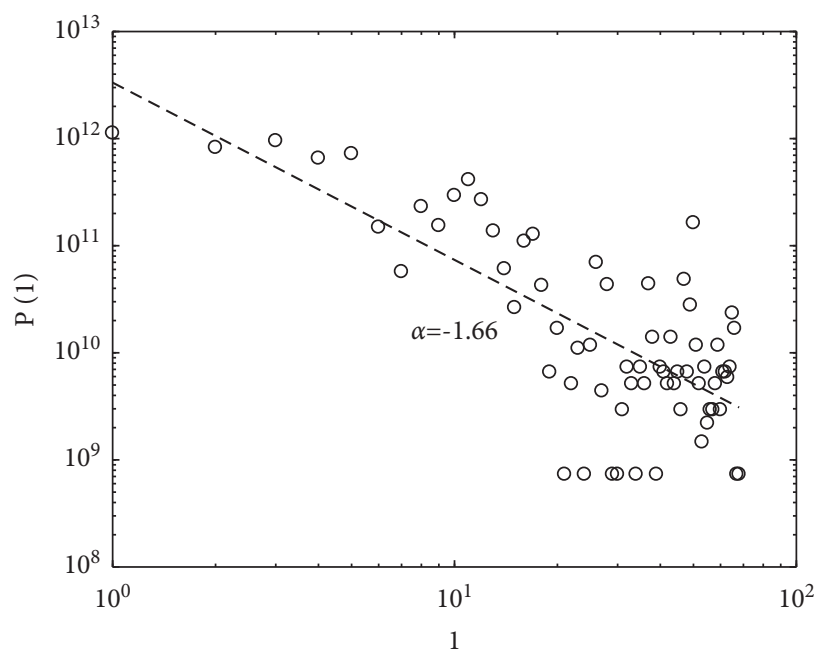

(a)

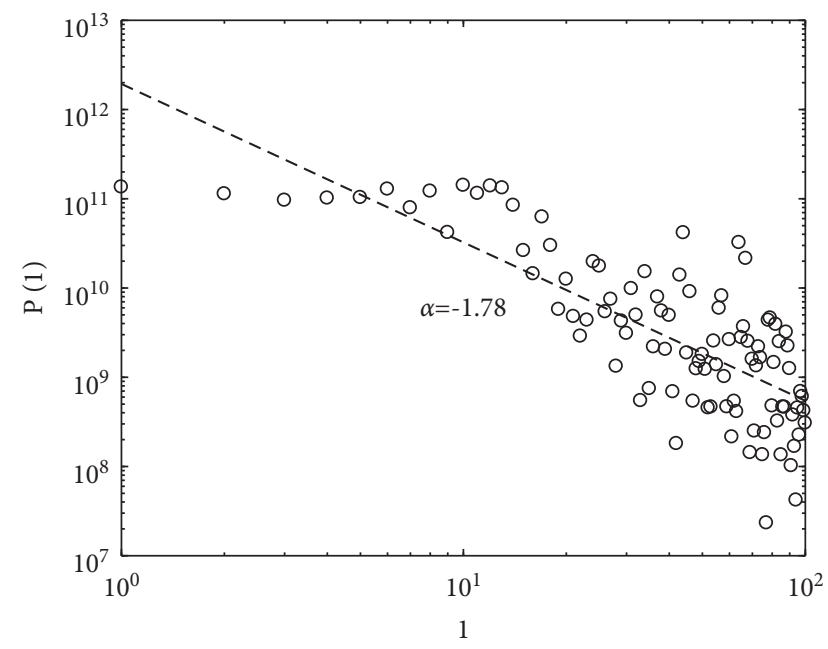

(b)

Figure 2: Distribution of interbank loans.

\section{Regulatory Interventions}

We first simulated the evolutionary banking system in different levels of interbank counterparties and investment assets to explore the regulatory interventions. Figure 3 shows the intervention of interbank counterparties. The evidence demonstrates that the increased number of interbank counterparties, represented by $C$, generally harms the stability of the banking system. Our result contradicts classic studies that highlight the advantages of a high level of interbank counterparties in systemic risk decreases. In the real financial market, it is too hard to share shocks because of the small scale of interbank loans. Therefore, the increased numbers of interbank counterparties promote systemic risk. However, we can also see that there is an inappreciable promotion of increased interbank counterparties to systemic risk. This further validates the conclusion discussed in Section 4. 
TABle 2: Correlation coefficients on systemic risk.

\begin{tabular}{lccc}
\hline & Market risk & Liquidity risk & Devaluation risk \\
\hline$D^{\prime}$ & $0.4390(0.0557)$ & $0.3669(0.1494)$ & $0.0704(0.0612)$ \\
$D^{\prime \prime}$ & $0.7939(0.0438)$ & $0.4617(0.1112)$ & $0.3258(0.0365)$ \\
$L$ & $0.5916(0.1264)$ & $0.2973(0.0906)$ & $0.4550(0.1398)$ \\
\hline
\end{tabular}

Note. Robust standard errors are in parentheses.

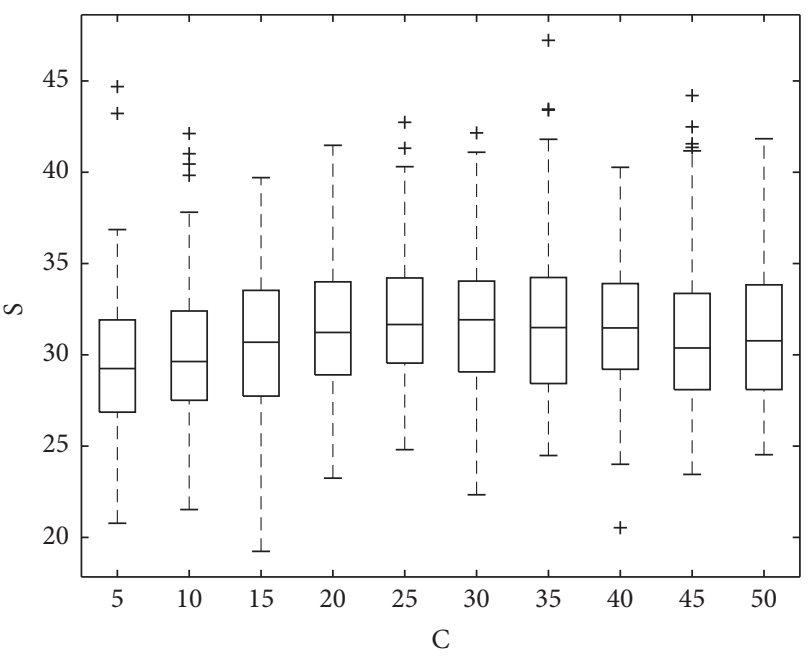

FIGURE 3: Interbank counterparties and systemic risk.

The intervention of investment assets is shown in Figure 4, where $M$ represents the average number of investment assets held by banks. Recall our assumption that banks evenly invest in all assets, the increased number of investment assets usually means a high level of common assets. Though common assets provide more channels for contagions, Figure 4 indicates that it significantly improves the banking system stability from the very beginning of the increasing number of investment assets. Diversified investment portfolios disperse the investment concentration, so the devaluation of assets formed by fire sales is limited. This weakens the contagion risks, hinting at the possibility of promoting systemic stability by incentivizing more diversification among banks.

According to the above results, fire sales show important effects on systemic risk by devaluating investment assets. In the benchmark case, all experiments follow a downside limit, $r=0.8$, in prices. Figure 5 further compares the evolution of systemic risk in the benchmark case $r=0$ and in the case $r=0.8$ without a limit-down rule. It shows that the systemic risk is much serious without a limit-down rule of asset prices in terms of both frequency and degree due to contagions formed by fire sales. The observation indicates that fire sales of assets contribute critically to systemic risk.

We further explore the interventions of different monetary policies in dealing with systemic risk, especially liquidity facilities from the central bank. To demonstrate the value of prudential liquidity requirements, all experimental results in Table 3 are divided into two groups, where only the deposit reserve ratios are supervised in "DRA" and both the deposit reserve ratios and the liquidity coverage ratios are supervised in "DRA and LCR." The comparison shows that the liquidity coverage ratio requirement promotes prudential behaviors of the banks and then improves the banking system stability. Specifically, Table 3 shows the comparison of interbank policies where interbank loans are, respectively, formed by interbank lending and interbank repurchases. The main difference between them is in securities. This discussion is motivated by the fact that interbank repurchase is much higher than interbank borrowing in terms of volume, although unsecured interbank loans are widely modeled in most of the studies. The result shows that despite the benefits to individual banks, interbank repurchase will aggravate the vulnerability of the whole banking system, since the security requirement harms the investment returns of illiquid banks, which becomes a cause of systemic risk.

Moreover, three common monetary policies were simulated to explore the advantage of the central bank in the modern financial system. The result of open market operation and central bank lending is listed in the rest of Table 3, and the deposit reserve ratio is shown in Figure 6. It is worth noting that after considering the liquidity facility of the central bank through open market operation, the liquidity coverage ratio requirement of illiquid banks should be updated to make the cash outflow include securities. Both open market operation and central bank lending can effectively alleviate systemic risk caused by liquidity shortages to prevent serious fire sales and systemic risk. As with the interbank market, an open market operation that relies on 


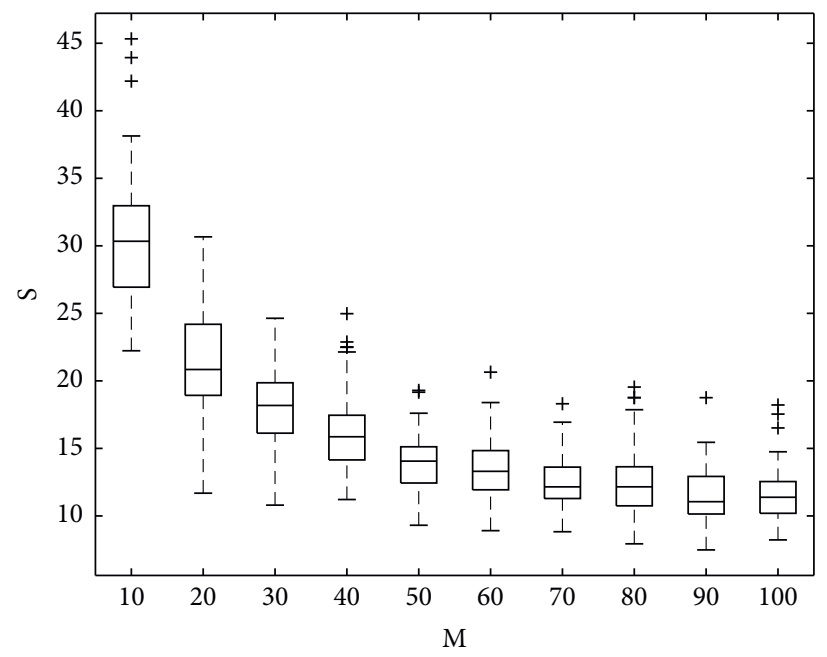

FIgURE 4: Investment assets and systemic risk.
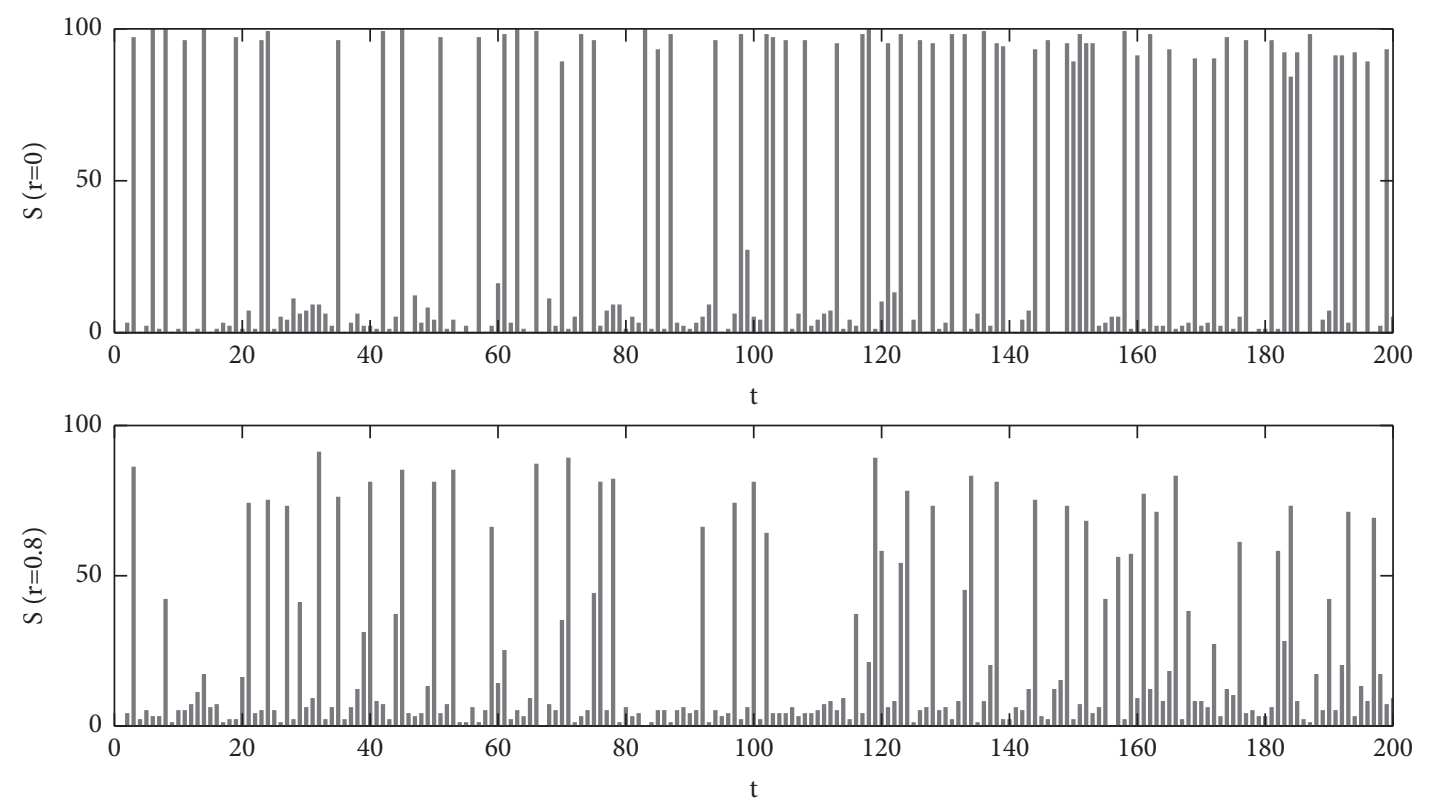

FIGURE 5: Limit-down rule and systemic risk.

TABle 3: Systemic risk with different kinds of monetary policies.

\begin{tabular}{lcccccccc}
\hline & \multicolumn{2}{c}{ Interbank lending } & \multicolumn{2}{c}{ Interbank repurchase } & \multicolumn{2}{c}{ Open market operation } & \multicolumn{2}{c}{ Central bank lending } \\
& DRA & DRA and LCR & DRA & DRA and LCR & DRA & DRA and LCR & DRA & DRA and LCR \\
\hline Mean & 30.3238 & 25.1154 & 41.8972 & 40.6311 & 12.0323 & 10.2306 & 7.0385 & 5.2768 \\
Std. & 3.7949 & 4.6807 & 3.3009 & 3.8194 & 5.8078 & 5.9008 & 5.8222 & 4.8197 \\
$N$ & 100 & 100 & 100 & 100 & 100 & 100 & 100 & 100 \\
\hline
\end{tabular}

necessary security mortgage harms the expected investment returns, which will increase systemic risk compared with central bank lending.

Figure 6 shows the effect of the deposit reserve ratio on systemic risk. With the deposit reserve ratio cuts, more liquidity is released to the investments, and insufficient liquidity is reserved for banks to cope with large deposit withdrawals. Therefore, the systemic risk increases with the initial deposit reserve ratio cuts. However, with the continuous deposit reserve ratio cuts, in which case liquidity is sufficient for interbank loans, illiquid banks have enough access to liquidity facilities through the interbank market to meet deposit withdrawals. At this time, the systemic risk of the whole banking sector is 


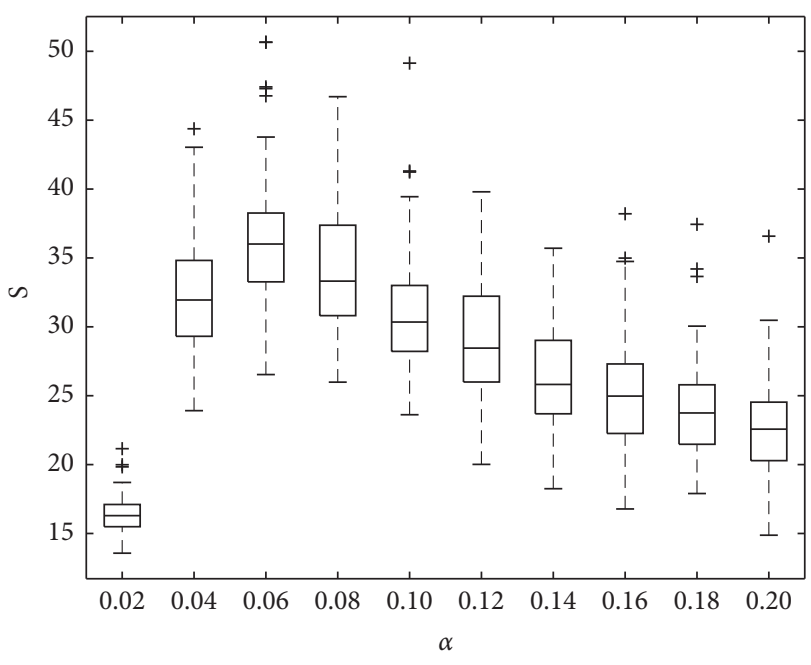

FIgURE 6: Deposit reserve ratio and systemic risk.

reduced. This result indicates a threshold effect of deposit reserve ratio cuts, which provides a regulatory reference for improving systemic stability.

\section{Conclusion}

An agent-based model is proposed and calibrated to explore the effect of interbank loans and common assets on systemic risk. The results show that the systemic risk consists of the market risk, liquidity risk, and devaluation risk, which are determined by investment losses, liquidity shortages, and fire sales, respectively. All the factors are related to interbank loans and common assets, which are the main causes of contagion risks. Further study shows that the systemic risk is seriously caused by fire sales. Although many studies highlight the spiral effect of interbank loans and common assets on promoting systemic risk, our results indicate that interbank loans provide an inappreciable promotion for contagions in the cascade of fire sales when compared to common assets. Accordingly, increased interbank counterparties barely reduce systemic risk. However, regulatory interventions suggest that the systemic risk could be effectively weakened by diversified investment assets and the limit-down rule in prices.

The interventions related to different monetary policies in dealing with systemic risk are also explored. Experimental results demonstrate the advantages of prudential liquidity requirements, interbank liquidity facilities, and monetary policies from the central bank. In contrast to general studies, we define interbank repurchases instead of interbank lending as interbank liquidity facilities, because of the much higher volume of interbank repurchases in the real banking system. We find that interbank repurchases aggravate the vulnerability of the full banking system, though it is beneficial for individual banks. This study also proposed the threshold effect of deposit reserve ratio cuts, in which the systemic risk increases with the initial deposit reserve ratio cuts and decreases with the continuous deposit reserve ratio cuts to a certain value. This result may provide a regulatory reference for improving systemic stability.

\section{Data Availability}

The data used to support the findings of this study are available from the corresponding author upon request.

\section{Disclosure}

Jingqian Tian and Chao Wang should be regarded as cocorresponding authors and co-first authors.

\section{Conflicts of Interest}

The authors declare that they have no conflicts of interest.

\section{Authors' Contributions}

Jingqian Tian and Chao Wang contributed equally to the work.

\section{Acknowledgments}

This research was supported by the National Natural Science Foundation of China (no. 72173018) and the Humanities and Social Science Fund of Ministry of Education of China (21YJC790108).

\section{References}

[1] D. Di Gangi, F. Lillo, and D. Pirino, "Assessing systemic risk due to fire sales spillover through maximum entropy network reconstruction," Journal of Economic Dynamics and Control, vol. 94, pp. 117-141, 2018.

[2] I. Aldasoro and I. Alves, "Multiplex interbank networks and systemic importance: an application to European data," Journal of Financial Stability, vol. 35, pp. 17-37, 2018.

[3] P. Alessandri, P. Gai, S. Kapadia, N. Mora, and C. Puhr, "Towards a framework of quantifying systemic stability," International Journal of Central Banking, vol. 5, no. 3, pp. 47-81, 2009.

[4] A. Gurgone, G. Iori, and S. Jafarey, "The effects of interbank networks on efficiency and stability in a macroeconomic agent-based model," Journal of Economic Dynamics and Control, vol. 91, pp. 257-288, 2018.

[5] E. Batiz-Zuk, F. López-Gallo, and S. Martínez-Jaramillo, "Calibrating limits for large interbank exposures from a system-wide perspective," Journal of Financial Stability, vol. 27, pp. 198-216, 2016.

[6] S. Battiston and S. Martinez-Jaramillo, "Financial networks and stress testing: challenges and new research avenues for systemic risk analysis and financial stability implications," Journal of Financial Stability, vol. 35, pp. 6-16, 2018.

[7] S. Battiston, D. D. Gatti, M. Gallegati, B. Greenwald, and J. E. Stiglitz, "Default cascades: when does risk diversification increase stability?" Journal of Financial Stability, vol. 8, no. 3, pp. 138-149, 2012.

[8] M. Elliott, B. Golub, and M. O. Jackson, "Financial networks and contagion," The American Economic Review, vol. 104, no. 10, pp. 3115-3153, 2014.

[9] S. Battiston, G. Caldarelli, M. D’Errico, and S. Gurciullo, "Leveraging the network: a stress-test framework based on debtrank," Statistics \& Risk Modeling, vol. 33, no. 3-4, pp. 117-138, 2016. 
[10] P. Tasca and S. Battiston, "Market procyclicality and systemic risk," Quantitative Finance, vol. 16, no. 8, pp. 1219-1235, 2016.

[11] V. V. Acharya and O. Merrouche, "Precautionary hoarding of liquidity and interbank markets: evidence from the subprime crisis," Review of Finance, vol. 17, no. 1, pp. 107-160, 2013.

[12] S. H. Lee, "Systemic liquidity shortages and interbank network structures," Journal of Financial Stability, vol. 9, no. 1, pp. 1-12, 2013.

[13] P. Smaga, M. Wiliński, P. Ochnicki, and T. Gubiec, "Can banks default overnight? modelling endogenous contagion on the $\mathrm{O} / \mathrm{N}$ interbank market," Quantitative Finance, vol. 18, no. 11, pp. 1815-1829, 2018.

[14] D. Acemoglu, A. Ozdaglar, and A. Tahbaz-Salehi, "Systemic risk and stability in financial networks," The American Economic Review, vol. 105, no. 2, pp. 564-608, 2015.

[15] F. Allen and D. Gale, "Financial contagion," Journal of Political Economy, vol. 108, no. 1, pp. 1-33, 2000.

[16] P. Gai, A. Haldane, and S. Kapadia, "Complexity, concentration and contagion," Journal of Monetary Economics, vol. 58, no. 5, pp. 453-470, 2011.

[17] D. Ladley, "Contagion and risk-sharing on the inter-bank market," Journal of Economic Dynamics and Control, vol. 37, no. 7, pp. 1384-1400, 2013.

[18] E. Nier, J. Yang, T. Yorulmazer, and A. Alentorn, "Network models and financial stability," Journal of Economic Dynamics and Control, vol. 31, no. 6, pp. 2033-2060, 2007.

[19] P. Glasserman and H. P. Young, "How likely is contagion in financial networks?" Journal of Banking \& Finance, vol. 50, pp. 383-399, 2015.

[20] C. P. Georg, "The effect of the interbank network structure on contagion and common shocks," Journal of Banking \& Finance, vol. 37, no. 7, pp. 2216-2228, 2013.

[21] T. Roukny, S. Battiston, and J. E. Stiglitz, "Interconnectedness as a source of uncertainty in systemic risk," Journal of Financial Stability, vol. 35, pp. 93-106, 2016.

[22] L. Sun, "Financial networks and systemic risk in China's banking system," Finance Research Letters, vol. 34, Article ID 101236, 2020.

[23] M. Teteryatnikova, "Systemic risk in banking networks: advantages of "tiered" banking systems," Journal of Economic Dynamics and Control, vol. 47, pp. 186-210, 2014.

[24] F. Caccioli, J. D. Farmer, N. Foti, and D. Rockmore, "Overlapping portfolios, contagion, and financial stability," Journal of Economic Dynamics and Control, vol. 51, pp. 50-63, 2015.

[25] W. Guo, A. Minca, and L. Wang, "The topology of overlapping portfolio networks," Statistics \& Risk Modeling, vol. 33, no. 3-4, pp. 139-155, 2016.

[26] C. Upper, "Simulation methods to assess the danger of contagion in interbank markets," Journal of Financial Stability, vol. 7, no. 3, pp. 111-125, 2011.

[27] L. Eisenberg and T. H. Noe, "Systemic risk in financial systems," Management Science, vol. 47, no. 2, pp. 236-249, 2001.

[28] N. Beale, D. G. Rand, H. Battey, R. Croxson, M. May, and M. A. Nowak, "Individual versus systemic risk and the regulator's dilemma," Proceedings of the National Academy of Sciences, vol. 108, no. 31, pp. 12647-12652, 2011.

[29] F. Caccioli, M. Shrestha, C. Moore, and J. D. Farmer, "Stability analysis of financial contagion due to overlapping portfolios," Journal of Banking \& Finance, vol. 46, pp. 233-245, 2014.

[30] Z. Feinstein, "Financial contagion and asset liquidation strategies," Operations Research Letters, vol. 45, no. 2, pp. 109-114, 2017.
[31] B. Li, X. Liu, and C. Wang, "The topology of indirect correlation networks formed by common assets," Physica A: Statistical Mechanics and Its Applications, vol. 528, Article ID 121496, 2019.

[32] W. Wagner, "Diversification at financial institutions and systemic crises," Journal of Financial Intermediation, vol. 19, no. 3, pp. 373-386, 2010.

[33] T. Kobayashi, "Network versus portfolio structure in financial systems," The European Physical Journal B, vol. 86, no. 10, p. $434,2013$.

[34] J. Ma, J. He, X. Liu, and C. Wang, "Diversification and systemic risk in the banking system," Chaos, Solitons \& Fractals, vol. 123, pp. 413-421, 2019.

[35] D. O. Cajueiro and B. M. Tabak, "The role of banks in the Brazilian Interbank Market: does bank type matter?" Physica A: Statistical Mechanics and Its Applications, vol. 387, no. 27, pp. 6825-6836, 2008.

[36] G. Iori, G. De Masi, O. V. Precup, G. Gabbi, and G. Caldarelli, "A network analysis of the Italian overnight money market," Journal of Economic Dynamics and Control, vol. 32, no. 1, pp. 259-278, 2008.

[37] I. Aldasoro, D. Delli Gatti, and E. Faia, "Bank networks: contagion, systemic risk and prudential policy," Journal of Economic Behavior \& Organization, vol. 142, pp. 164-188, 2017.

[38] P. Tasca, S. Battiston, and A. Deghi, "Portfolio diversification and systemic risk in interbank networks," Journal of Economic Dynamics and Control, vol. 82, pp. 96-124, 2017.

[39] Y. Amihud and J. Noh, "Illiquidity and stock returns II: crosssection and time-series effects," Review of Financial Studies, vol. 34, no. 4, pp. 2101-2123, 2021. 